\title{
Prospecções sobre a relação entre as comunidades do bairro Reis Católicos (Alcalá de Henares, Madrid) e seus bens arqueológicos
} Alejandra Saladino ${ }^{1}$ e Alicia Castillo-Mena

Introdução

Ideias convergentes sobre temáticas de interesses em comum levaram-nos a iniciar alguns estudos em conjunto. Essas pesquisas enfocam as estratégias de gestão arqueológica em cidades ibero-americanas declaradas Patrimônio Mundial pela UNESCO, partindo do princípio da importância de desenvolver processos participativos baseados em estudos de percepção social para alcançar resultados verdadeiramente significativos para a

\footnotetext{
${ }^{1}$ Alejandra Saladino - Professora do Departamento de Estudos e Processos Museológicos da Universidade Federal do Estado do Rio de Janeiro e do Mestrado Profissional em Preservação do Patrimônio Cultural do Instituto do Patrimônio Histórico e Artístico Nacional e museóloga do Museu da República

alejandrasaladino@gmail.com

Alicia Castillo-Mena - Professora do Departamento de Pré-História da Universidade Complutense de Madrid e do Mestrado em Preservação do Patrimônio Cultural da mesma Universidade. Presidenta do ICOMOSEspanha.

alicia.castillo@ghis.ucm.es
} 
preservação e interpretação dos bens e para a mudança social, e ainda as relações entre o patrimônio cultural e as comunidades nos mais distintos contextos urbanos. A uma dessas pesquisas está dedicado este artigo.

Ela resulta de uma experiência-piloto realizada nas etapas finais do projeto I+D "La Dimensión Arqueológica en ciudades Patrimonio Mundial: avances para la gestión patrimonial en Alcalá de Henares, Puebla y La Habana", coordenado por Alicia CastilloMena, do Grupo de Gestão do Patrimônio Cultural da Universidade Complutense de Madrid (UCM). Essa investigação, iniciada em 2007, objetivava levantar e analisar os desafios referentes ao processo de valorização e gestão dos bens arqueológicos (CASTILLO, 2016a; CASTILLO, 2016b; CASTILLO, 2015) $)^{2}$.

Por sua vez, o estudo aqui apresentado resultou de um desdobramento, ou melhor, o aprofundamento sobre um aspecto específico em relação à cidade de Alcalá de Henares: a relação entre os vizinhos e a dimensão arqueológica do bairro Reis Católicos. Em concreto, trata-se das ruínas musealizadas de uma cidade romana, Complutum, situada nos dias atuais em um bairro da periferia do município.

Reis Católicos é um bairro do II Distrito II da cidade, circunscrito em uma área de $3.987 \mathrm{~km}^{2}$. Foi o primeiro bairro da cidade projetado para solucionar o problema de escassez de moradias decorrente do grande afluxo de pessoas que se transladaram para a região atraídas pela oferta de trabalho nas indústrias das cercanias. Àquela altura, o bairro era habitado por cidadãos de toda a Espanha. Entretanto, a vizinhança tornou-se mais diversificada cultural e etnicamente. Hoje, o bairro é caracterizado por uma multiculturalidade característica das metrópoles, com comunidades de ciganos (as que primeiro chegaram) e europeus do Leste (dos quais se destacam os romenos), além de latino-americanos, africanos subsaarianos e chineses.

2 O projeto finalizou em 2017 com a realização das Jornadas de Arqueología, no Museo Arqueológico Nacional de Madrid. 
A motivação para realizar uma pesquisa de campo piloto nos meses de novembro de 2015 e junho de 2016 adveio da inquietação referente ao tipo de relação possível entre essa comunidade heterogênea e em situação de exclusão e vulnerabilidade social com um sítio arqueológico musealizado com poucas conexões evidentes com as memórias dessas pessoas.

Além da questão central do estudo, motivou-nos a possibilidade de experimentar e avaliar a aplicação de distintas técnicas de campo para a coleta de dados sobre o objeto de estudo, nomeadamente o flanêur e a deriva.

Objetivamos com este artigo apresentar os resultados desta experiência. Para tal, faz-se necessário apresentar um breve panorama sobre Complutum e sua vizinhança, o bairro Reis Católicos. Na sequência são expostas as etapas de campo, destacando as metodologias aplicadas e os dados coletados. Ao final, é apresentada uma possível interpretação dos resultados e ainda uma avaliação das metodologias em tela.

Complutum e Reis Católicos: dois mil anos de ocupação e ressignificação da paisagem

Alcalá de Henares é um munícipio da Comunidade Autônoma de Madrid com uma longa história. Os percursos do tempo nesse espaço remontam à Pre-História, mas destacam-se os marcos dos períodos da Península Ibérica romanizada e islamizada. Essa cidade patrimônio mundial apresenta uma curiosa característica: o translado do centro urbano em distintas épocas. Atualmente, o centro da cidade corresponde ao centro histórico das épocas medieval e moderna, dos quais se destacam alguns marcos da paisagem urbana, como a Rua Maior e a Universidade de Alcalá, apenas para citar alguns.

Outros marcos da memória alcalaína se encontram fora dessa zona: são os monumentos romanos Casa de Hipolitus e as ruínas da cidade de Complutum. A intensificação dos estudos, iniciados no século XVI, e a musealização in situ dos remanescentes de Complutum conectam-se à necessidade de urbanizar a zona 
periférica de Alcalá de Henares para a construção das moradias para os operários das fábricas das cercanias, entre os anos 1960 e 1980. Essa área corresponde ao segundo distrito do município, que possui quatro.

O Segundo Distrito reúne algus bairros onde também são encontrados numerosos centros educativos e de saúde, além de bibliotecas e outras instituições de cunho social. De acordo com o estudo de geografía humana de González e Torres (2012:277), é esta a zona que apresenta o maior número de imigrantes de toda a comunidade autônoma de Madrid, sendo ultrapassada apenas pela própria capital do país. A pesquisa também ressaltou que os bairros Reis Católicos e Juncal (este último justo ao lado de Complutum) são as áreas do II Distrito com o maior número de imigrantes da cidade, e mais, a zona que apresenta o maior nível de multiculturalidade.

Miradas sobre Complutum desde o bairro Reis Católicos: ensaios metodológicos

Quando propusemos investigar a relação que a vizinhança de Reis Católicos tem com as ruínas musealizadas de Complutum já tínhamos alguns dados empíricos sobre ela, que indicavam nãoi haver qualquer conexão.

Frente a algumas provocações - como por exemplo "qual o sentido desse monumento clássico para a vizinhança multicultural, para a qual o passado do império romano pouco ou nada diz?" e "é possível que esses remanescentes tenham algum sentido para essas pessoas?) - pusémonos a pensar se Complutum estaria então condenada a nada significar e representar para seus vizinhos.

Entretanto, coincidimos em relação a alguns aspectos que nos levam a pensar que as referências patrimoniais podem ser reinterpretadas, e mais, que podem ser úteis para a mudança da realidade das pessoas, ainda que a princípio não seja evidente a "ressonância" ${ }^{3}$ entre elas e o patrimônio cultural. O primeiro refere-

\footnotetext{
${ }^{3}$ Tomando por base estudo de Gonçalves (2005), compreendemos o termo "ressonância" como faculdade do objeto ultrapassar suas fronteiras
} 
se à capacidade que bens culturais têm de ressignificação ao longo do tempo e em relação às demandas e necessidades das sociedades do tempo presente. O segundo diz respeito à função social do patrimônio cultural, que vale a pena ser aproveitado desde suas dimensões cultural e econômica se o mote for o aumento da qualidade de vida das pessoas ${ }^{4}$. O terceiro tem a ver com la principal coriente de pensamiento na filosofía e na ética da ciência" (MARTÍNEZ, 2006:25). Em outras palavras, coincidimos com o arqueólogo Vítor Martínez para quem a "ciência não pode desentender-se de seus resultados práticos, as decisões 'técnicas' dos especialistas não devem obedecer somente a interesses científicos, mas também devem ser guiadas por diretivas políticas e éticas de interesse social" (MARTíNEZ, 2006:25). O quarto aspecto diz respeito à percepção pós-colonialista à crítica epistemológica multiculturalista de que a ciência moderna é apenas uma das muitas formas de conhecimento que existem.

Comprendemos que, em um contexto de multiculturalidade ${ }^{5}$ é importante construir, da forma mais horizontal possível um discurso dialógico e polifônico sobre o patrimônio cultural e implantar práticas inclusivas por meio de ações integradas e participativas. Para alcançar este objetivo é importante desenvolver estudos de percepção social e

formais e representar e evocar aspectos sócio-culturais, como, por exemplo, memórias e identidades.

${ }^{4}$ Compreendemos o conceito de qualidade de vida de forma ampla, ou seja, significando a emancipação e empoderamento social e também sustentabilidade, conforto e segurança para as pessoas.

${ }^{5}$ Sobre o conceito de "multiculturalidade", concidimos com o antropólogo Terence Turner (1993) quando afirma ser necessário distanciar-se da perspectiva "multiculturalista diferencialista", que essencializa o conceito de "cultura" e promove a separaçãon entre os grupos, e aproximar-se da "multuculturalista crítica", ou seja, considerando a cultura como uma forma de consciência social e de que as diferenças são produzidas ao longo de processos sócio-históricos de relações assimétricas (TURNER, 1993:417). 
metodologias participativas, estratégias que que propomos para nosso objeto de estudo.

Com estes eixos conceituais passamos à coleta de dados, tomando como referência os pricípios da Museologia Social e ainda alguns recursos metodológicos das ciências sociais e antropológicas. Decidimos pela Museologia Social como diretriz de nossa pesquisa sobre a relação entre Complutum a vizinhança assim que tomamos conhecimento dos dados empíricos anteriormente citados e também aqueles publicados no estudo de González e Torres (2012). Comprendemos que em um contexto tão complexo como o do bairro Reis Católicos, caracterizado pelas tensões entre alguns moradores, a sociedade multicultural e em risco de exclusão e vulnerabilidade social e as excavações em Complutum, é importante enfrentar o desafio de transformar os museus - no caso um sítio arqueológico musealizado - em algo que possibilite uma mudança positiva na vida das pessoas, nem que seja somente no tocante à percepção sobre estas instituições, de fontes de dispêndio dos poucos recursos financeiros disponíveis a motores de desenvolvimento a partir da cultura e do patrimônio, como assinala o Conselho Internacional de Museus/ICOM (2013a; 2013b). Afinal, coincidindo com o poeta e museólogo Mario Chagas (2013), se miramos com as lentes da Museologia Social, observamos que as pessoas são o grande patrimônio ${ }^{6}$.

Em Reis Católicos: estratégias de aproximação e resultados obtidos

Nossa investigação sobre a relação entre os restos musealizados de Complutum e sua vizinhança desenvolveu-se em duas etapas. Antes da aproximação física, realizamos uma revisão bibliográfica sobre o processo de patrimonialização da cidade e da

${ }^{6}$ Destacamos que essa perspectiva é consonante ao primeiro artigo do código de conduta da American Anthropological Association, concretamente no seguinte trecho: "a responsabilidade maior dos antropólogos é para com as pessoas que estudiam, acima de qualquer outra consideração social, política ou científica" (PELS apud MARTÍNEZ, 2006:59). 
gestão de Complutum, vinculada à atuação das Escolas-oficinas e da criação do Serviço de Arqueologia do município, em $1998^{7}$. Procuramos por mapas e esquemas para compreender a disposição das áreas reconhecidas como patrimônio mundial e também dos bairros vizinhos ao sítio arqueológico.

Dedicimos avançar sobre o campo como se fôssemos turistas, ainda que considerássemos os princípios de uma técnica específica, que se trata da metáfora do flâneur (BENJAMIN, 1994). Escolhemos esse método pois nossa intenção consistia na coleta de dados sobre a transitoriedade do panorama urbano de Complutum e seu entorno como se este fosse um texto onde pudéssemos, desde uma mirada poética, encontrar "correspondências" entre o passado e o presente (ABREU, 2012:24), nas quais observássemos os processos de ressemantização de Complutum.

Em nossa primeira incursão, observamos a insuficiente sinalização a indicar a direção do sítio. Iniciamos a caminhada na Praça Porta de Santa Ana e avançamos sobre o bairro pela Rua Núñez Guzmán. Finalmente, na rua Nossa Senhora de Belém (Figura 1) econtramos uma placa de sinalização da direção de Complutum.

Figura 1 - Mapa do Bairro Reis Católicos, Alcalá de Henares

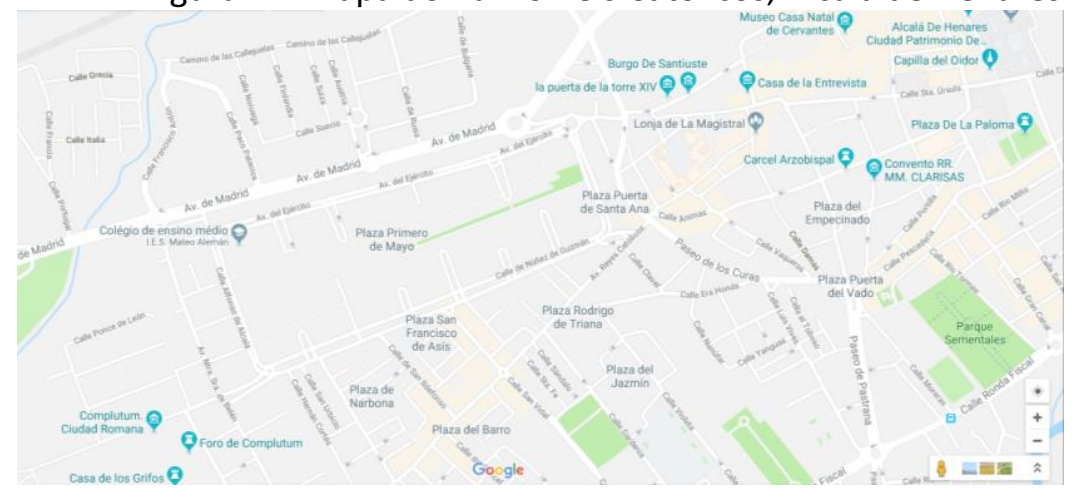

${ }^{7}$ Para maiores informações sobre a gestão de Complutum, ver a obra de Ana Lucía Sánchez Montes e colaboradores (2014). 
Fonte: https://www.google.com.br/maps/@40.4784811,$\underline{3.3760564,16 z}$

Os recursos metodológicos utilizados nesta etapa foram:

a) observação assistemática: desenvolvida a partir da técnica do flâneur, para coletar e registrar informações sobre o conhecimento e reconhecimento dos vizinhos sobre Complutum, sem planjear ou controlar. Os dados obtidos dizem respeito ao cotidiano das pessoas que moram no bairro e sobre o conhecimento da existência do sítio arqueológico;

b) observação sistemática: análise e descrição dos elementos e ações que ocorrem em um espaço em um determinado momento. Os dados obtidos dizem respeito às dinâmicas sociais geradas em Complutum e seu entorno em distintos períodos do dia, ao longo da pesquisa de campo;

c) diário de campo: registro diário das atividades desenvolvidas e também das impressões acerca do que foi observado. Os dados obtidos referem-se aos registros das facilidades e dificuldades do trabalho de campo;

d) fotografias fixas: a pulso e em lugares determinados. Os resultados obtidos referem-se ao registro de momentos pontuais para analisar um mesmo liugar ao longo do tempo e, em especial, o fluxo de pessoas à entrada do sítio arqueológico musealizado;

e) mapa de possíveis steakholders: identificação de agentes envolvidos em ações sócio-culturais no bairro, desde uma participação ativa e também passiva. Os resultados obtidos dizem respeito à identificação de atores sociais na prefeitura, nas paróquias Nossa Senhora de Belém e São Francisco de Assis e o Centro Cívico María Zambrano, por exemplo;

f) observação participativa: análise e descrição das visitas guiadas em Complutum. Os resultados obtidos referem-se 
ao registro das dinâmicas produzidas em torno à visita e das reações dos visitantes;

g) entrevistas abertas: com alguns agentes sociais, sem gravador, para criar um ambiente mais cômodo, informal, amigável e de confiança. O objetivo principal centrava-se na evocação das memórias sobre determinados eventos (como, por exemplo, a participação nas escavações e nas oficinas-escolas, as transformações sofriadas pelo bairro ao longo do tempo e a chegada de novas comunidades de imigrantes). Os resultados obtidos referem-se ao registro da opinião das pessoas a respeito do sítio e sua relação com a vizinhança;

h) recursos visuais (fotografias do sítio arqueológico): utilizados durante as entrevistas e a observação assistemática em lugares de sociabilidade, como bares e no Centro Cívico María Zambrano, para estimular a lembrança de alguns fatos e eventos, previamente levantados na revisão bibliográfica;

i) registros fotográficos sistemáticos: realizados durante as entrevistas e as visitas ao sítio, com o objetivo de complementar os dados de nossa pesquisa.

$\mathrm{Na}$ segunda etapa de campo objetivávamos realizar uma contagem das pessoas que passavam por alguns lugares do bairro e ainda uma "prospecção" para identificar os possíveis marcos de memória (Halbwachs, 1990) dos vizinhos de Complutum.

Como anteriormente mencionado, tencionávamos experimentar distintos métodos aplicáveis no campo. Confeccionamos um instrumento que resultou da adaptação e da combinação das fichas de prospecção arqueológica comumente utilizadas para o registro dessa etapa de campo e do conjunto de fichas que compõem o Inventário Nacional de Registro de Referências Culturais do IPHAN do Brasil $^{8}$. Este instrumento é aplicado nos processos de registro de bens culturais intangíveis

${ }^{8}$ Ver www.iphan.gov.br. 
como patrimônios culturais e possui uma forte vertente antropológica que resulta interesante para coletar dados sócioculturais dos próprios bens avaliados e do próprio ambiente no qual se manifiestam.

Foi então elaborado um conjunto de fichas a partir das quais foi possível tomar nota dos distintos marcos da paisagem, das manifestações e práticas culturais a eles relacionados, dos agentes sociais envolvidos e dos registros fotográficos e audiovisuais realizados. Essas fichas foram planejadas para servirem de instrumento para a sistematização de informações de todo tipo sobre a vizinhança de Complutum.

A coleta dos dados deu-se a partir de uma técnica específica, a principal ferramenta dos estudos da psicogeografía ${ }^{9}:$ a deriva. Trata-se precisamente de um procedimento psicogeográfico, por meio do qual é possível tomar nota dos efeitos do ambiente sobre as pessoas que nele habitam e transitam; é uma forma de analisar e decifrar as interações entre os agentes e os contextos, buscando coletar dados sobre o comportamento afetivo e os sistemas perceptivo e cognitivo. Graças à deriva é possível coletar dados sobre os marcos materiais e outros que se destacam e que caracterizam o entorno de Complutum, levando em consideração as emoções e sensações provocadas pela paisagem.

A técnica apresenta outra característica que motivou nossa escolha: o papel do acaso na coleta de dados. Na deriva define-se um ponto de partida específico, mas não um trajeto pré-definido. Os percursos são decididos ao longo do caminhar, são resultado dos efeitos do ambiente sobre as pessoas.

Decidimos utilizar a técnica como um experimento com vistas a descolonizar o olhar sobre os marcos espaciais da memória do bairro. Nossa tentativa era identificar os bens da vizinhança aos

9 Psicogeografia: linha de estudos do ambiente utilizada no âmbito da Geografia Humana com o objetivo de estudar os efeitos do ambiente urbano sobre as pessoascom o fim de transformar positivamente as cidades. Para aprofundar sobre o tema, ver Ontañón (2012). 
quais poderíamos identificar variados critérios de valoração de referências patrimoniais, ainda que não institucionalizados.

Levando em consideração as dimensões do bairro e o escasso tempo de que dispúnhamos para realizar o trabalho, decidimos desenvolvê-lo em uma área específica do II Distrito, a mais próxima de Complutum, e dividimo-la em duas zonas. A Zona A correspondia ao trecho da avenida de Madrid e o Caminho do Juncall/rua Núñez Guzmán, entre a rua Antonio Suárez e a rua Demetrio Ducas. A Zona B correspondia ao trechodo Caminho do Juncal/rua Núñez Guzmán e a avenida Reis Católicos, entre a rua Antonio Suárez e a rua Demetrio Ducas.

A prospecção foi a primeira atividade desenvolvida, seguida da contagem das pessoas a transitar ou permanecer em marcos espaciais da memória do bairro. A primeira ação foi desenvolvida em duas etapas: a primera foi realizada com os estudantes vinculados ao Grupo de Pesquisa Gestão do Patrimônio Cultural e a subsequente foi relizada apenas pela autora do texto. A contagem também foi desenvolvida em duas fases: a primeira, igualmente junto aos estudantes, e a segunda, sozinha.

Na primeira etapa da prospecção formamos dois grupos, 1 e 2, que iniciaram os percursos nas zonas A e B, partindo da rua Antonio Suárez até a rua Demetrio Ducas. Cuando os grupos chegavam ao final do trajeto, mudavam de zona. Assim, o grupo que iniciou a deriva na Zona A, finalizava na Zona B e vice-versa.

As atividades relacionadas à prospecção foram repartidas entre os participantes. Enquanto tomavam nota dos marcos espaciais, as práticas sócio-culturais observadas e os contatos estabelecidos no mapa do bairro, outros registravam as motivações das decisões que resultaram no delineamento dos trajetos percorridos nas zonas (por exemplo, as escolhas de parar em algum lugar, de virar à esquerda ou direita, de seguir por uma rua, de conversar com os vizinhos ou perguntar-lhes algo relacionado a um 
marco espacial específico ${ }^{10}$ ), além de outros registros relacionados à técnica da deriva ${ }^{11}$. Outros participantes fotografavam a paisagem urbana e ainda faziam pequenos vídeos com o telemóvel.

No tocante à primeira etapa de contagem dos marcos espaciais, vale destacar que a mesma foi realizada por três grupos, dispostos em dois pontos distintos da zona estudada: em Complutum, na praça logo ao lado do sítio, onde se encontra a Sede de Petanca Arqueológica, e na rua Magalhães, onde há uma praça maior. Já a segunda etapa de contagem foi realizada apenas em Complutum.

Nas fichas reunimos as informações sobre os marcos edificados e outros materiais da paisagem, incluindo a paisagem "natural", além das respectivas práticas sócioculturais manifestadas no momento da prospeç̧ão (como, por exemplo, as reuniões dos pensionistas na praça ao lado da rua Núñez Guzmán y dos jogadores da Petanca Arqueológica). Em uma ficha específica, reunimos dados sobre a experiência da deriva, com informações sobre as impressões gerais sobre os percursos, as imagens e sons de cada área etc.

${ }^{10}$ A deriva foi realizada da forma mais livre possível, os participantes apenas receberam algumas sugestões: caminhar e parar de acordo com a percepção do espaço e dos moradores que neles estavam; levar em consideração que, a priori, todas as casas são bonitas, ou seja, que fossem observadas para além dos valores patrimoniais de excepcionalidade e monumentalidade, apenas para citar alguns e procurar por marcos espaciais mais antigos e mais recentes, levando em consideração a aparência dos mesmos bem como as narrativas dos moradores a respeito do tema. Os participantes da deriva foram estimulados e provocados com algumas perguntas a potencializar a atividade, mas sem o intuito de conduzir a experiência. A título de ilustração, convidamo-los a pensar sobre: os lugares (edifícios, áreas específicas etc) que pudessem possuir algum tipo de valor patrimonial, os aspectos da paisagem urbana que gostaram e desgostaram, as sugestões de alterações e, por fim das coisas a preservar.

${ }^{11}$ Designadamente, os odores, as mudanças de temperatura ao longo do percurso, a reação das pessoas etc. 


\section{Análise e interpretação dos resultados}

Nas etapas da pesquisa de campo, coletamos dados quantitativos e qualitativos da zona periférica de Alcalá de Henares, contígua ao perímetro reconhecido como patrimônio da humanidade. As duas técnicas de aproximação do objeto estudado possibilitaram descolonizar nossa mirada sobre a zona. Foi possível observar que todas as casas são bonitas, pois que repletas de memórias, coisas boas de lembrar - e de esquecer também - ainda que não estejam completamente encaixadas nos princípios que regem os processos de valoração das referências patrimoniais.

Sobre Complutum, partindo de um olhar estrangeiro, percebemos a naturalização do passado hispano-romano, ou seja, a memória histórica, romanizada, põe-se em evidência e impõe-se. Vale sublinhar que as narrativas dessa memória advêm de atores sociais representantes das classes dominantes. Indagamo-nos então se os vizinhos do bairro analisado podem identificar-se com essas lembranças essencializadas, que são a base do discurso museográfico do sítio. Graças às observações assistemáticas e participante da primeira etapa da investigação, podemos responder a essa pergunta de maneira negativa. O passado e o discurso científico hegemônico, ambos essencializados, não permitem que os vizinhos se identifiquem com as memórias aderidas nos restos arqueológicos nem mesmo aquelas que poderiam ser articuladas com o cotidiano do presente (designadamente, aquelas que são expostas no percurso referente ao mercado de Cumplutum). Nossa percepção é que tais dados são apresentados desde uma perspectiva alheia, de difícil ressonância com as identidades e as memórias de um bairro multicultural.

Entretanto, compreendemos que o sítio faz sim parte das memórias dessas pessoas, principalmente e de forma mais evidente e direta com aqueles envolvidos com o passado industrial de Alcalá de Henares e cercanias. Em nosso estudo preliminar, identificamos alguns vizinhos do bairro que trabalharam nessas fábricas e outros, seus descendentes, que fizeram os cursos de formação técnica 
oferecidos pelas escolas-oficinas da região. Alguns que permaneceram na zona encontram-se desempregados ou desempenhando funções laborais em outras áreas. Apenas uma aluna egressa dos diversos cursos técnicos que tiveram Complutum como laboratório está a trabalhar neste sítio. Uma informante relatou a decepção de não ter ingressado no mercado de trabalho como técnica em arqueologia, apesar de ter participado dos cursos de pedreiro e restaurador de mosaico. Podemos considerar que os dados coletados sugerem a desarticulação das políticas públicas que não resultaram na absorção da mão-de-obra qualificada pelas oficinas-escola da região.

Atualmente, há no sítio uma placa de sinalização e informação a identificar os responsáveis por sua preservação, que inclui a própria sociedade. Inácio Díaz Balerdi (2015) nos faz lembrar de que os discursos não são negociados, mas disputados, e nos recomenda chamar à responsabilidade as pessoas a respeito da preservação e proteção de suas referências patrimoniais. Entretanto, receamos pela eficácia de um letreiro - a informar de que o patrimônio é da sociedade e que é necessário preservá-lo para ressaltar o valor patrimonial de um bem cultural e para comprometer a população nesses processos. Faz-se mister um conjunto de ações integradas e participativas para a obtenção de resultados positivos. Seria pertinente experimentar uma ecologia de saberes (Sousa Santos, 2007) em Complutum, e criar um discurso museográfico horizontal e que considerasse os saberes e percepções dos vizinhos do sítio sobre o passado da região.

A técnica do flanêur nos permitiu aproximar das pessoas de uma forma mais sutil. Dito de outra forma, sem interrogá-las diretamente sobre os temas de interesse de nossa investigação. Quando Ihes perguntávamos sobre a localização do sítio no bairro, ou se já o haviam visitado ou se tinham alguma lembrança dele, o fazíamos como indagações próprias de uma conversa entre um turista e um local, ou seja, os moradores estavam no controle do diálogo, e as respostas dependentes de sua vontade de responder e manter a conversa ou não. 
Por outro lado, nas organizações do bairro por nós visitadas em busca de identificar os stakeholders, a situação foi distinta. Nesses contextos necessitávamos apresentarnos e aos objetivos de nosso estudo. Em duas instituições sociais distintas, obtivemos a mesma resposta: os vizinhos do bairro têm necessidades "mais urgentes" que desfrutar do patrimônio arqueológico da região.

De toda maneira, os resultados da primeira etapa da investigação aqui apresentada coincidem com os dados empíricos coletados previamente. Os moradores de Reis Católicos, principalmente aqueles que vivem mais próximos a Complutum, são aqueles que emprestam ao bairro os tons mais vivos de sua multiculturalidade. Como os vizinhos dos anos 1980, encontram-se em uma situação de vulnerabilidade social, ainda que por distintas razões $^{12}$.

Os dados coletados durante a observação sistemática e assistemática em alguns pontos específicos do bairro ${ }^{13}$ sugerem que os vizinhos circulam pouco pela cidade, deslocando-se excepcionalmente até o centro da cidade. Para a grande maioria das pessoas que estabelecemos contato em ambas as etapas de campo, o bairro não está mal. As queixas e reclamações referem-se aos serviços da municipalidade, como limpeza, e com longa permanência de alguns segmentos sociais, concretamente, a comunidade cigana, a que primeiro ocupou o bairro, originalmente habitado pelos operários das fábricas e outras famílias de menor podere aquisitivo.

12 Durante a observação participante desenvolvida em dois bares da região, as memórias ativadas assinalavam que, na década de 1980, a situação de exclusão de e vulnerabilidade social associavam-se ao tráfico e ao consumo de drogas e à prostituição. Hoje, os relatos dos vizinhos associam essa característica do bairro ao alto índice de desemprego e à permanência de alguns grupos, historicamente marginalizados, como os ciganos.

${ }^{13}$ As praças do Caminho do Juncal, na rua Magalhães, o mercado León e os bares El Momento e La Mezquita. 
Graças aos dois métodos aplicados, logramos identificar elementos significativos de uma mudança evidente nas áreas limítrofes entre o bairro e outras zonas da cidade, especialmente o centro histórico. As diferenças podem ser percebidas com os sentidos. Com os olhos podemos identificar uma diferença da arquitetura das moradias (conjuntos de edifícios de ladrilhos aparentes e de muitos andares), a quantidade de roupa a secar (que pode ser indício da existência de famílias numerosas) e de lixo espalhado nas suas, a variedade de tons e formas das roupas usadas pela gente, igualmente de muitas e distintas cores, que caracterizam o bairro Reis Católicos. Com os ouvidos podemos identificar zonas onde há mais ruido (as escolas, os mercados, a praça mais grande da rua Magalhães, alguns pátios entre os edifícios localizados entre a avenida do Exército e a rua Núñez de Guzmán e também os distintos idiomas falados pelos vizinhos. Com o nariz confirmamos que muitas áreas do bairro cheiram a lixo, e que algumas ruas cheiram a lavanda e outras flores, como por exemplo, a avenida Reis Católicos, nas proximidades do Arboleto, uma espécie de jardim e parque do bairro.

Entretanto é necessário sublinhar ainda a experiência da deriva, compartilhada com os estudantes da UCM, na qual todos tivemos a mesma impressão de haver uma espécie de uma barreira invisível na praça da rua Demétrio Ducas. Esse muro intangível coincide com a fronteira entre o bairro e outras áreas da cidade, da qual destacamos o centro histórico declarado patrimônio mundial.

É possível ainda elencar outros resultados da deriva:

a) o Arboleto foi mencionado por alguns vizinhos como uma das melhoras coisas do bairro. Assim, é possível compreendê-lo como um marco espacial das memórias mais recentes, visto que o jardim/parque foi construído há pouco mais de dez anos;

b) os cartazes e outros marcos espaciais (designadamente os letreiros dos estabelecimentos comerciais da zona) não fazem 
qualquer referência nem a Complutum nem ao passado romano da região ${ }^{14}$;

c) os vizinhos demonstraram incômodo com as práticas de campo realizadas, especialmente os registros fotográficos durante a deriva. Vale ressaltar que essa atmosfera desconfortável foi mais percebida justamente na área do caminho do Juncal, com maior concentração de imigrantes e com maior índice de desemprego;

d) durante a segunda etapa de campo, realizada no início do verão, observamos que as pessoas mantêm o hábito de encontrar-se nas praças e outros lugares de sociabilidade, mas concentram-se nas zonas arborizadas, onde há sombra. Vale sublinhar a formação de grupos marcadamente definidos pela faixa etária e pelos traços étnico-culturais;

e) em um dos edifícios mais antigos do bairro, localizado na área limítrofe com o centro histórico, os estabelecimentos comerciais são mais cuidados e reformados que os existentes na zona que corresponde ao caminho do Juncal;

f) o bar situado no Centro Cívico María Zambrano parece ser um importanto ligar de encontro e sociabilidade da vizinhança multicultural. Por isso, caso fosse possível desenvolver alguma atividade de reinterpretação de Complutum por meio de ações participativas com os grupos sociais ali presentes, parece-nos pertinente que fosse ali desenvolvida.

No tocante à atividade de contagem das pessoas a passar e permanecer em alguns pontos específicos do bairro ${ }^{15}$, na primeira etapa obtivemos os resultados expostos no Quadro 1:

${ }^{14}$ É comum, em áreas onde a dimensão arqueológica é reconhecida e valorizada, que os estabelecimentos comerciais adotem nomes que the façam menção. A título de ilustração, destacamos a cidade de Mérida, com pastelarias e outras lojas com nomes que remetem ao passado romano.

${ }^{15}$ A atividade foi realizada entre as $10: 40 \mathrm{~h}$ e las $14 \mathrm{~h}$ do dia 22 de junho de 2016. 
Quadro 1:

Contagem - Etapa 1

\begin{tabular}{|l|c|c|c|c|}
\hline & $\begin{array}{l}10: 40- \\
12: 00\end{array}$ & $\begin{array}{c}12: 01- \\
13: 00\end{array}$ & $\begin{array}{c}13: 01 \\
14: 00\end{array}$ & Total \\
\hline Sítio & - & - & - & 0 \\
\hline Entraram em Complutum & 25 & 30 & 10 & 65 \\
\hline Passaram por Complutum & 138 & 32 & 4 & 174 \\
\hline $\begin{array}{l}\text { Passaram pela Praça ao } \\
\text { lado de Complutum }\end{array}$ & 48 & 15 & 10 & 73 \\
\hline $\begin{array}{l}\text { Permaneceram na praça ao } \\
\text { lado de Complutum }\end{array}$ & 233 & 182 & 90 & 505 \\
\hline $\begin{array}{l}\text { Passaram pela rua } \\
\text { Magalhães }\end{array}$ & & & & \\
\hline
\end{tabular}

Durante a segunda etapa da contagem ${ }^{16}$, realizada somente em Complutum, logramos reunir os seguintes dados: 73 personas passaram pela entrada do sítio arqueológico musealizado, mas ninguém entrou. Finalmente, a terceira e última etapa da contagem ${ }^{17}$, también realizada apenas no sítio, coletamos os seguintes dados: 84 pessoas passaram pela entrada, mas nenhuma entrou.

A faixa etária que correspondem às pessoas contadas ao longo do desenvolvimento da atividade é bem marcada: crianças e adolescentes, além dos pensionistas. A observação durante a contagem sugere que adolescentes e pensionistas permanecem um tempo na praça pequena justo ao lado de Complutum - os primeiros sentados a conversar e os segundos a jogar petanca/bocha. Já na praça maior, à rua Magalhães, há uma concentração de crianças e adolescentes. Vale ressaltar que é esse o espaço de sociabilidade em melhor estado de conservação e com

\footnotetext{
${ }^{16}$ Realizada entre as $17 \mathrm{~h}$ e as 19:00h do dia 22 de junho de 2016.

${ }^{17}$ Realizada entre as $17 \mathrm{~h}$ e as $20 \mathrm{~h}$ do dia 23 de junho de 2016.
} 
mais ofertas de brinquedos infantis. Entretanto, quando realizávamos a deriva na área, os vizinhos confundiram-nos com agentes da municipalidade e pediram-nos que tomássemos providências para a melhoria da praça, como o conserto de alguns brinquedos e a instalação de mais bancos.

Os dados coletados durante a deriva e a contagem indicam resultados semelhantes aos coletados no trabalho de campo da etapa anterior. Em outras palavras, embora realizássemos as atividades em estações do ano distintas, os vizinhos continuam a passar pela entrada do sítio arqueológico musealizado sem grande interesse em visitá-lo. Preferem permanecer na praça justo ao lado, com mais bancos e mais áreas com árvores e, portanto, sombra.

\section{Algumas notas finais}

Compreendemos que Complutum é um importante marco na paisagem e um ponto turístico pouco aproveitado devido à realidade do bairro no qual se situa. Concretamente, localiza-se fora da área declarada patrimônio da humanidade, num bairro com um histórico de exclusão e vulnerabilidade social. No passado recente, as ruínas da cidade romana foram utilizadas para desenvolver ações de inclusão dos jovens moradores do bairro, filhos dos operários das fábricas. No futuro, Complutum pode ser o mote para o desenvolvimento de ações integradas e participativas com vistas a melhorar a qualidade de vida de seus moradores e, em consequência, como num círculo virtuoso, o estabelecimento de programas e projetos interinstitucionais com vistas a valorizar e a socializar o próprio bem cultural. Inserir as comunidades nos procesos museológicos e integrar os museus com o público são posibilidades reais, desde que baseadas em ações integradas e participativas, nas quais o conhecimento científico multidisciplinar compõe, com outras formas de saberes, o discurso patrimonial da zona. Em resumo, compreendemos ser possível a ressemantização de Complutum tornando-o um sítio construído e aberto para os vizinhos, no entrelaçamento da Sociomuseologia e da Arqueologia Social. 
Agradecimentos

Agradecemos a Sebastián Rascón, Diretor do Serviço de Arqueologia de Alcalá de Henares, à equipe do Coletivo Caje, pela acolhida, pelas conversas e pelo apoio necessário para coletar dados sobre a complexidade social do bairro, aos colegas do Grupo de Pesquisa Gestão do Patrimônio Cultural da UCM pelo apoio, aos estudantes do curso de Arqueologia pelo auxílio na realização da segunda etapa de campo e, em especial, aos moradores do bairro Reis Católicos, pela compreensão e permissão para intervir em seu cotidiano.

\section{Bibliografia}

ABREU, Regina. Colecionando museus como ruínas: percursos e experiências de memoria no contexto de açoes patrimoniais. I/ha, v.14, n.1, jan/jun 2012, p.17-35 < file:///C:/Documents\%20and\% 20Settings/Maria/Mis\%20documentos/Downloads/26316-92048-3-

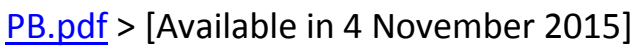

Acosta, Alberto (2013), El buen vivir. Sumak Kawsay, una oportunidad para imaginar otros mundos. Barcelona: Icaria.

BALERDI, Iñaki Díaz (2015). Mecánicas emocionales y proyectivas en las estrategias de activación patrimonial y museística. Complutum, 2015, v.26(2), p.165-173.

<file://C:/Documents\%20and\%20Settings/Maria/Mis\%2 0documentos/Downloads/50427-89745-2-PB.pdf $>$ [Available in 4 November 2015]

BARROT, Jean. Crítica a la Internacional Situacionista. Editorial Klinamen. Cominización, 2009.

BENJAMIN, Walter (1994). Obras escolhidas III: Charles Baudelaire um lírico no auge do capitalismo. São Paulo: Brasiliense.

CASTILLO, Alicia. Introduction: Lights and shadows on the interpretation of Cultural Heritage through community-engaged participation. Complutum, 2016a, Vol. 27 (2): 253-258

CASTILLO, Alicia. Relaciones entre ciudadanía y agentes patrimoniales desde la perspectiva de la investigación académica: retos pendientes en la gestión del patrimonio cultural. 
PERSPECTIVAS | revista ph Instituto Andaluz del Patrimonio Histórico no 90 octubre 2016b, pp. 205-207

CASTILLO, A. Mapping stakeholders in archaeological heritage management. Dries, M. van den, J. van der Linde \& A. Strecker (eds.) Fernweh: Crossing borders and connecting people in archaeological heritage management. Essays in honour of prof. Willem J.H. Willems. Leiden: Sidestone Press, 2015, p.64-67.

FERREIRA, J. C. M. da S. (2007). A flor da terra: o cemitério dos pretos novos no Rio de Janeiro. Rio de Janeiro: Garamond/IPHAN.

CASTILLO, Alicia, YÁÑEZ, Ana; DOMÍNGUEZ, Marta; SALTO-WEISS, Isabel (2014). Citinzenship and Heritage Commitment: looking for Participatory Methodologies adopted to the Urban Cultural, context. 18th ICOMOS General Assembly, p.415-421

CHAGAS, Mário (2013), "El gran patrimonio de un museo es el público: Mario Chagas", Periódico El Tiempo.com, de 27 de setembro.

<http://www.eltiempo.com/entretenimiento/arte/ARTICULO-WEB NEW_NOTA_INTERIOR-13086708.html. > [Available in 15 November 2015]

GONÇALVES, J. R. Ressonância, materialidade e subjetividade: as culturas como patrimônios. Horizontes Antropológicos, v.11, n.23, Porto Alegre, p.15-36, Jan/Jun 2005.

< http://www.scielo.br/pdf/ha/v11n23/a02v1123.pdf > [Available in 4 November 2015]

GONZÁLEZ, M. J. y LÁZARO Y TORRES, M. L. (2012). La distribución espacial de la población inmigrante en dos ciudades medias: Alcalá de Henares y León y su relación con los precios de las viviendas. Anales de Geografía, v.32, n.2, p.275-295.

ICOM (2013a), "Viability and Sustainability of Museums through the Global Financial Crisis".

Resolução aprovada pela Assembleia-Geral do ICOM, Conferência Geral do ICOM, Rio de Janeiro, a partir da Declaração de Lisboa. ICOM (2013b), "Support Culture and Museums to Face the Global Crisis and Build the Future"(Lisbon Declaration). < 
http://www.icomportugal.org/multimedia/Lisbon\%20Declaration_A pril_2013(1).pdf. > [Available in 4 November 2015]

MINOM (2013), Declaração MINOM Rio 2013, V Conferência Internacional do MINOM, Rio de Janeiro, 8-10 de agosto de 2013. < http://www.minom-icom.net/files/declaracao-do-rio-minom.pdf. > [Available in 4 November 2015]

MARTíNEZ, V. M. F. (2006). Una Arqueología Crítica: ciencia, ética y política en la construcción del pasado. Barcelona: Editorial Crítica.

MONTES, Ana Lúcia et al. Guía-catálogo de Complutum, Ciudad Romana. Guías Arqueológicas de Alcalá de Henares, 1. Alcalá de Henares: Ayuntamiento de Alcalá de Henares, 2014.

MOUTINHO, M. (1989). Museus e socidade: reflexoes sobre a funcao social do museu. Caderno de patrimonio, 1989.

MOUTINHO, M. (1993). Sobre o conceito de Museologia Social. Cadernos de Sociomuseologia, n.1., 1993.

ONTAÑóN, A. (2012). 'La vanguardia no se rinde': Guy Debord y el Situacionismo. Situaciones, n.1. <http://situaciones.info/revista/lavanguardia-no-se-rinde-guy-debord-y-el-situacionismo/ > [Available in $4 \mathrm{Nov}$ 